\title{
Some take-home messages from the 9th International Meeting on Pulmonary Rare Diseases and Orphan Drugs
}

\author{
Sergio Harari $\mathbb{1}^{1,2}$, Yochai Adir ${ }^{3}$ and Marc Humbert $\mathbb{\circledR}^{4,5,6}$
}

${ }^{1}$ U.O. di Pneumologia e Terapia Semi-Intensiva Respiratoria - Servizio di Fisiopatologia Respiratoria ed Emodinamica Polmonare, Ospedale San Giuseppe - MultiMedica, IRCCS, Milan, Italy. ${ }^{2}$ Dept of Clinical Sciences and Community Health, Università di Milano, Milan, Italy. ${ }^{3}$ Pulmonary Division, Lady Davis Carmel Medical Center, Faculty of Medicine, The Technion Institute of Technology, Haifa, Israel. ${ }^{4}$ Université Paris-Saclay, Faculté de médecine - Inserm UMR-S 999, Le Kremlin-Bicêtre, France. ${ }^{5}$ Hôpital Marie Lannelongue, Assistance Publique-Hôpitaux de Paris (AP-HP), Le Plessis-Robinson, France. ${ }^{6}$ Service de pneumologie et soins intensifs respiratoires, Centre de référence de l'hypertension pulmonaire, Hôpital Bicêtre, Le Kremlin-Bicêtre, France.

Corresponding author: Sergio Harari (sergio@sergioharari.it)

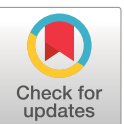

Copyright @The authors 2021

This version is distributed under the terms of the Creative Commons Attribution NonCommercial Licence 4.0. For commercial reproduction rights and permissions contact permissions@ersnet.org

Received: 22 Nov 2021 Accepted: 30 Nov 2021

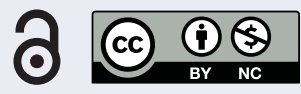

Shareable abstract (@ERSpublications)

The 9th International Meeting on Pulmonary Rare Diseases and Orphan Drugs was dedicated to the management of rare pulmonary parenchymal and vascular diseases and rare variants of more common respiratory conditions https://bit.ly/3rq7b95

Cite this article as: Harari S, Adir Y, Humbert M. Some take-home messages from the 9th International Meeting on Pulmonary Rare Diseases and Orphan Drugs. Eur Respir Rev 2021; 30: 210258 [DOI: 10.1183/16000617.0258-2021].
Dissemination of updated knowledge on rare and ultra-rare respiratory diseases has always been a priority of the European Respiratory Review $(E R R)$ [1, 2]. In this issue, we publish the first of a collection of four articles that discuss hot topics with direct practical clinical consequences. First, Mackintosh et al. [3] review the challenges and controversies (which are not few!) in "interstitial pneumonia with autoimmune features" (IPAF). Following the publication, in 2015, of the classification of IPAF proposed by the European Respiratory Society (ERS) and the American Thoracic Society (ATS) [4], a number of articles have been published on this entity which truly requires a multidisciplinary approach. Airway and vascular involvement are discussed in detail, as well as the problem of severe vasculopathy that can characterise some IPAF patients. The authors also discuss the controversial issue of the therapeutic approach for this "research entity" and state that "while identification of a histological NSIP pattern would support an immunosuppressive approach, histological confirmation of a UIP pattern would lead to a more cautious approach to immunosuppression, with frequent monitoring and earlier consideration of anti-fibrotic therapy, should there be progression” [3].

Second, BandyopadhyAy et al. [5] address the challenge of the perioperative management of patients with precapillary pulmonary hypertension $(\mathrm{PH})$ undergoing noncardiac non-obstetric surgery. When compared with elective surgery, emergency noncardiac procedures are associated with more perioperative complications and increased likelihood of worse outcome [6]. Haemodynamic ventricular interdependence and the possible causes of right ventricular failure and of its prevention are addressed in detail. The use of inotropes and of other drugs is a critical issue that is also reviewed carefully, together with the intraoperative management and monitoring, as well as ventilation and post-operative care.

Third, a forthcoming article by S. Tomassetti and co-workers reviews the challenging and poorly understood topic of interstitial lung abnormalities and its possible progression to idiopathic pulmonary fibrosis or to progressive fibrosing interstitial lung disease. Radiological definition and clinical implications are reviewed in detail.

The final article was written by a multidisciplinary group of experts invited by the World Association of Sarcoidosis and other Granulomatous Disorders (WASOG). In this WASOG statement on the diagnosis and management of sarcoidosis-associated PH, SAVALE et al. [7] present updated information on this severe complication of sarcoidosis. This statement is timely in the context of the recent publication of the ERS clinical practice guidelines on treatment of sarcoidosis [8-10]. 
Several of these articles derive from invited lectures and debates which took place during the digital ninth International Meeting on Pulmonary Rare Diseases and Orphan Drugs. This conference was endorsed by the European Reference Network on rare respiratory diseases (ERN-LUNG), a network of healthcare providers dedicated to the care and investigation of patients suffering from rare respiratory diseases (https:// ec.europa.eu/health/ern/networks_en) [11]. This international conference, held every other year, is entirely devoted to the management of rare pulmonary parenchymal and vascular diseases and rare variants of more common respiratory conditions such as severe refractory asthma. We thank the $E R R$ for once again publishing articles from this conference and hope that our readers will enjoy this selection, we are hopeful the 10th international meeting will be hosted face-to-face in 2023.

Provenance: Commissioned article, peer reviewed.

Conflict of interest: S. Harari reports personal fees from Roche, grants from AstraZeneca, grants and personal fees from Boehringer Ingelheim, outside the submitted work. Y. Adir reports personal fees from Teva, grants and personal fees from GSK, grants and personal fees from AstraZeneca, personal fees from Sanofi, personal fees from Bayer, grants and personal fees from Janssen, personal fees from Pfizer, outside the submitted work. M. Humbert reports grants, personal fees and other from Acceleron, grants, personal fees and other from Janssen, grants, personal fees and other from Merck, outside the submitted work; he has participated on advisory boards for Acceleron, Janssen, Merck and United Therapeutics.

\section{References}

$1 \quad$ Harari S. Why we should care about ultra-rare disease. Eur Respir Rev 2016; 25: 101-103.

2 Harari S, Adir Y, Humbert M. Rare pulmonary disease and orphan drugs: a path to the future. Eur Respir Rev 2019; 28: 190115.

3 Mackintosh JA, Wells AU, Cottin V, et al. Interstitial pneumonia with autoimmune features: challenges and controversies. Eur Respir Rev 2021; 30: 210177.

4 Fischer A, Antoniou KM, Brown KK, et al. An official European Respiratory Society/American Thoracic Society research statement: interstitial pneumonia with autoimmune features. Eur Respir J 2015; 46: 976-987.

5 Bandyopadhyay D, Lai C, Pulido JN, et al. Perioperative approach to precapillary pulmonary hypertension in non-cardiac non-obstetric surgery. Eur Respir Rev 2021; 30: 210166.

6 Meyer S, McLaughlin VV, Seyfarth HJ, et al. Outcomes of noncardiac, nonobstetric surgery in patients with PAH: an international prospective survey. Eur Respir J 2013; 41: 1302-1307.

7 Savale L, Huitema M, Shlobin O, et al. WASOG statement on the diagnosis and management of sarcoidosis-associated pulmonary hypertension. Eur Respir Rev 2022; in press [https://doi.org/10.1183/ 16000617.0165-2021].

8 Simonneau G, Montani D, Celermajer DS, et al. Haemodynamic definitions and updated clinical classification of pulmonary hypertension. Eur Respir J 2019; 53: 1801913.

9 Waxman A, Restrepo-Jaramillo R, Thenappan T, et al. Inhaled treprostinil in pulmonary hypertension due to interstitial lung disease. N Engl J Med 2021; 384: 325-334.

10 Baughman RP, Valeyre D, Korsten P, et al. ERS clinical practice guidelines on treatment of sarcoidosis Eur Respir J 2021; 58: 2004079.

11 Humbert M, Wagner TO. Rare respiratory diseases are ready for primetime: from Rare Disease Day to the European Reference Networks. Eur Respir J 2017; 49: 1700085. 